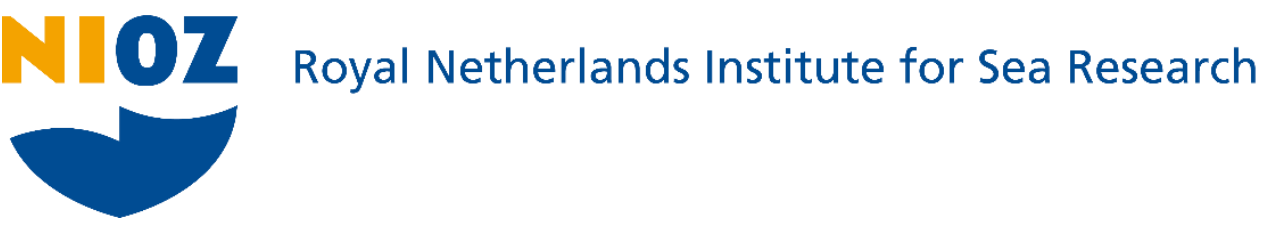

This is a postprint of:

Gledhill, M., Gerringa, L.J.A., Laan, P. \& Timmermans, K.R. (2015). Heme $b$ quotas are low in Southern Ocean phytoplankton. Marine Ecology Progress Series, 532, 29-40

Published version: $\underline{d x . d o i . o r g / 10.3354 / m e p s 11345 ~}$

Link NIOZ Repository: www.vliz.be/nl/imis?module=ref\&refid=249277

[Article begins on next page]

The NIOZ Repository gives free access to the digital collection of the work of the Royal Netherlands Institute for Sea Research. This archive is managed according to the principles of the Open Access Movement, and the Open Archive Initiative. Each publication should be cited to its original source - please use the reference as presented.

When using parts of, or whole publications in your own work, permission from the author(s) or copyright holder(s) is always needed. 


\section{Heme $b$ quotas are low in Southern Ocean phytoplankton}

4

6 Martha Gledhill*1,2,3 ${ }^{1,}$ Loes J. A. Gerringa ${ }^{2}$, Patrick Laan ${ }^{2}$ and Klaas R. Timmermans ${ }^{2}$

$7{ }^{1}$ Ocean and Earth Science, University of Southampton, National Oceanography Centre, Southampton, $8 \mathrm{SO} 143 \mathrm{ZH}, \mathrm{UK}$

92 Department of Biological Oceanography, Royal Netherlands Institute for Sea Research, PO Box 59, 10 AB Den Burg (Texel), The Netherlands 


\section{Abstract}

Heme is the iron containing prosthetic group of hemoproteins, and is thus required for photosynthesis, respiration and nitrate reduction in marine phytoplankton. Here we report

21 concentrations of heme $b$ in Southern Ocean phytoplankton and contrast our findings with those

22 in coastal species. The concentration of particulate heme $b\left(\mathrm{pmol} \mathrm{L}^{-1}\right)$ observed at the end of the 23 exponential growth phase was related to the concentration of dissolved iron in the culture media. 24 Small Southern Ocean phytoplankton species $(<6 \mu \mathrm{m}$ in diameter) had heme $b$ quotas $<1 \mu$ mol $25 \mathrm{~mol}^{-1}$ carbon, the lowest yet reported for marine phytoplankton. Heme $b$ was also depleted in 26 these species with respect to chlorophyll $a$. We calculated the amount of carbon accumulated per 27 mole of heme $b$ per second in our cultures (heme growth efficiency, HGE) and found that small 28 Southern Ocean species can maintain growth rates, even while heme $b$ content is reduced. Small 29 Southern Ocean phytoplankton can thus produce more particulate carbon than larger Southern 30 Ocean or small coastal species at equivalent iron concentrations. Combining primary 31 productivity and heme $b$ concentrations reported for the open ocean, we found that HGE in 32 natural populations was within the range of our laboratory culture results. HGE was also 33 observed to be higher at open ocean stations characterized by low iron concentrations. Our 34 results suggest that low heme $b$ quotas do not necessarily result in reduced growth and that 35 marine phytoplankton can optimize iron use by manipulating the intracellular hemoprotein pool. 


\section{Introduction}

Iron is an essential nutrient for life but is present at very low concentrations, typically less than 200 pmol L ${ }^{-1}$, in open ocean surface waters (De Baar \& De Jong 2001). As a result of low

41 ambient iron concentrations open ocean phytoplankton may have lower intracellular iron quotas

42 than coastal species (Sunda et al. 1991, Sunda \& Huntsman 1995, Strzepek et al. 2011), optimize

43 their iron use via reduction of iron rich proteins (Strzepek \& Harrison 2004), or exchange of iron

44 containing proteins with non-iron containing alternatives (Erdner et al. 1999, Peers \& Price

45 2006). Such changes appear to result in increased efficiency of growth in low iron environments

46 (Raven 1988, 1990, Strzepek et al. 2011).

The major iron containing protein pools in phytoplankton are dominated by proteins involved

48 in photosynthesis, nitrate reduction and respiration (Raven 1988, Strzepek \& Harrison 2004).

49 Hemoproteins are involved in electron transport and catalysis, and in the control, storage and

50 transport of oxygen and other small molecules (Hogle et al. 2014). Hemes, the prosthetic groups

51 of hemoproteins, contain one iron ion per molecule and many hemoproteins contain multiple

52 hemes (Smith et al. 2010). Hemes are synthesized on the same biosynthetic pathway as

53 chlorophyll and the molecules are related via their common tetrapyrrole ring structure (Tanaka \&

54 Tanaka 2007). Free heme is toxic (Espinas et al. 2012), so cellular heme concentrations are

55 tightly regulated via complex feedback mechanisms that control tetrapyrrole synthesis (Tanaka

$56 \&$ Tanaka 2007), and via heme oxygenase enzymes, which break down heme into biliverdins and

57 iron (Shekhawat \& Verma 2010). The heme iron reservoir could represent as much as $40 \%$ of

58 the total intracellular iron pool in marine phytoplankton (Raven 1988, Honey et al. 2013), in

59 circumstances where iron storage is not significant. 
Heme can also be a direct source of iron for marine bacteria, and there is evidence to suggest

61 that marine bacteria utilize specific uptake pathways in order to directly access this source of

62 iron (Hopkinson et al. 2008, Roe et al. 2013, Hogle et al. 2014). Hemoprotein concentrations are

63 known to vary in response to iron availability, and intracellular iron concentrations have been

64 shown to be a controlling factor for the biosynthesis of tetrapyrroles (Qi \& O'Brian 2002).

65 Diurnal cycling of hemoproteins in diazotrophic cyanobacteria (Saito et al. 2011), and increases

66 in heme oxygenase in red algae (Richaud \& Zabulon 1997) have been observed, suggesting that

67 the heme-iron pool may represent a relatively mobile intracellular iron reservoir. Intracellular

68 heme concentrations of marine phytoplankton growing in low iron environments might therefore

69 be expected to be reduced, with potential impacts both on iron demand and heme requiring

70 metabolic processes such as photosynthesis or nitrate reduction (Hogle et al. 2014).

71 Heme $b$ (iron protoporphyrin IX) is perhaps the most versatile and ubiquitous heme, and is

72 incorporated into hemoproteins such as the globins, cytochromes, catalase and oxidases. In

73 phytoplankton, heme $b$ makes up between 1 and $40 \%$ of the total cellular iron pool (Honey et al.

74 2013). However, no studies on heme abundance or regulation have so far been reported for

75 species isolated from iron limited regions of the ocean, although Gledhill et al. (2013) have

76 shown that concentrations of heme $b$ in particulate material in the iron limited high latitude

77 North Atlantic and in the Southern Ocean are deplete compared to more iron replete regions like

78 the tropical North Atlantic. There is thus a need to examine the heme $b$ quotas in phytoplankton

79 species originating from low iron regions of the ocean in order to better understand how marine

80 phytoplankton modify their heme $b$ protein pool when growing at low iron concentrations.

The aim of our study was therefore to investigate heme $b$ abundance in eukaryotic

82 phytoplankton species isolated from the Southern Ocean, one of the lowest iron environments in 
83 the ocean. We determined the concentrations of heme $b$ accumulated in phytoplankton grown in

84 Southern Ocean seawater at the end of the exponential growth phase. We compare heme $b$ to

85 iron concentrations in the cultures, to particulate organic carbon (POC) and to chlorophyll $a$ (chl

86 a). We utilized the concept of heme growth efficiency (HGE), which, in analogy to Raven (1988)

87 and Strzepek et al. (2011), we defined as the moles of C fixed per mole of heme $b$ per second. In

88 this way we examined the overall impact of reduced heme content on carbon fixation in our

89 phytoplankton cultures. We compared HGE calculated for our Southern Ocean phytoplankton

90 with that calculated from heme $b$ concentrations and primary productivity data for three sets of

91 previously published field data from contrasting regions - the Celtic Sea (Hickman et al. 2012,

92 Honey et al. 2013), the Scotia Sea (Korb et al. 2012, Gledhill et al. 2013) and the Iceland Basin

93 (Poulton et al. 2010, Gledhill et al. 2013) to assess the relationship between low heme $b$ and

94 phytoplankton productivity in the ocean.

\section{Materials and Methods}

\subsection{Phytoplankton growth conditions}

97 Batch cultures of Phaeocystis antarctica (CCMP 1871, isolated from the Bellinghausen Sea),

Chaetoceros brevis (CCMP 163, isolated from the Southern Ocean), C. dichaeta (NIOZ culture collection, isolated from the Southern Ocean) and P. globosa (NIOZ culture collection, isolated from the North Sea) were grown in triplicate in filtered Southern Ocean seawater (SOs, $0.2 \mu \mathrm{m}$,

101 Sartobran, Sartorius) previously collected using trace metal clean sampling techniques from

102 south of the Polar Front from a depth of 2-3 m using a "fish" towed from RV Polastern

103 (Expedition 18/2, November 2000). Cultures were maintained in acid washed (1 mol L ${ }^{-1}$

104 hydrochloric acid) and Milli-Q water rinsed, microwave sterilized polycarbonate bottles 
105 (Kawachi \& Noel 2005). Sample and culture manipulations were carried out in a class 100 106 laminar flow hood following trace metal clean protocols (Sunda et al. 2005). Southern Ocean 107 seawater was amended with the siderophore desferrioxamine (DFB, 5 nmol L${ }^{-1}$, Sigma) or $\mathrm{FeCl}_{3}$ $108\left(5 \mathrm{nmol} \mathrm{L}^{-1}\right)$ to create three treatments SOs, SOs+DFB and SOs+Fe. Phaeocystis globosa and $C$. 109 calcitrans (CCMP 1315, isolated from Japanese coastal waters) were grown in enriched SOs, 110 which contained added ethylenediaminetetraacetic acid (EDTA, $\left.100 \mu \mathrm{mol} \mathrm{L}^{-1}\right)$, cobalt (50 nmol $\left.111 \mathrm{~L}^{-1}\right)$, molybdenum $\left(100 \mathrm{nmol} \mathrm{L}{ }^{-1}\right)$, copper $\left(20 \mathrm{nmol} \mathrm{L} \mathrm{L}^{-1}\right)$, manganese $\left(115 \mathrm{nmol} \mathrm{L}^{-1}\right)$, zinc $(80$ $\left.112 \mathrm{nmol} \mathrm{L} \mathrm{L}^{-1}\right)$, selenium $\left(10 \mathrm{nmol} \mathrm{L}^{-1}\right)$ and $\mathrm{f} / 2$ vitamins. Iron was added separately from a stock 113 solution of $45 \mu \mathrm{mol} \mathrm{L}{ }^{-1}$ FeEDTA to obtain final concentrations of 9, 15, 45 and $150 \mathrm{nmol} \mathrm{L}^{-1}$. All 114 experiments were carried out using a 16:8 h light:dark cycle under cool white fluorescent lights 115 at $60 \mu \mathrm{mol}$ quanta $\mathrm{m}^{-2} \mathrm{~s}^{-1}$. Phaeocystis antarctica, C. brevis and C. dichaeta were grown at $4{ }^{\circ} \mathrm{C}$, 116 P. globosa at $15^{\circ} \mathrm{C}$ and $C$. calcitrans at $22{ }^{\circ} \mathrm{C}$. Cultures were maintained in experimental media

117 for $>6$ generations prior to experiments. For consistency, and to avoid issues arising from colony 118 formation in both Phaeocystis species, growth rates for all species were calculated from the slope 119 of the natural $\log \left(\mathrm{F}_{0}\right.$, autofluorescence) obtained for dim-light adapted (15 min) cells using a 120 PAM fluorometer (Walz, Germany) plotted against time. Cell abundance was also monitored 121 daily for C. brevis, C. calcitrans, and Phaeocystis sp., by flow cytometry (Accuri C6, BD 122 Biosciences, results not presented). Cultures of $P$. globosa, $P$. antarctica and $C$. dichaeta were 123 examined in $5 \mathrm{~mL}$ settling chambers by microscopy (Zeiss Axiovert 25 inverted microscope, 124 results not presented). The PAM fluorometer was used for daily determination of variable vs. 125 maximum fluorescence of photosystem II $\left(\mathrm{F}_{\mathrm{v}} / \mathrm{F}_{\mathrm{m}}\right)$. The experiments were terminated and cells 126 harvested when both cell numbers and fluorescence measurements indicated the exponential 127 growth phase was ending. 
129 Concentrations of the dissolved macro nutrients (nitrate + nitrite - termed nitrate for simplicity, 130 phosphate and silicate) were determined on filtered $(0.2 \mu \mathrm{m}, 25 \mathrm{~mm}$ Acrodisc, Pall Corp)

131 samples using a segmented flow autoanalyzer (Grasshoff et al. 1983; QuAAtro, SEAL

132 Analytical). Samples for nitrate and phosphate were frozen $\left(-20^{\circ} \mathrm{C}\right)$ prior to analysis, while 133 samples for silicate were kept at $4{ }^{\circ} \mathrm{C}$. The detection limit was typically $0.1,0.01$ and $0.1 \mu \mathrm{mol} \mathrm{\textrm {L } ^ { - }}$

$134{ }^{1}$ for nitrate, phosphate and silicate respectively. Total dissolved iron was determined by flow 135 injection analysis with chemiluminescence detection on acidified, filtered $(0.2 \mu \mathrm{m}$, Sartobran, 136 Sartorius) samples according to the methods described in De Baar et al. (2008). Ligand 137 concentrations and the associated conditional stability constants were determined on filtered 138 samples $(0.2 \mu \mathrm{m})$ by competitive equilibrium adsorptive cathodic stripping voltammetry (CE139 AdCSV) using 2-(2-thiazolylazo)-p-cresol (TAC) as the competing ligand (Croot \& Johansson 140 2000). Samples were frozen after collection and defrosted $24 \mathrm{~h}$ before analysis. Sample 141 manipulation and data treatment were carried out as described elsewhere (Gerringa et al. 2014).

\section{$142 \quad 3.3$ Analysis of phytoplankton}

143 Samples for particulate organic carbon (POC), nitrogen (PON), chlorophyll $a$ (chl $a$ ) and heme $b$ 144 were collected on glass fiber filters (pore size $0.7 \mu \mathrm{m}$, Whatman). Filters for POC and PON were 145 ashed prior to use $\left(400{ }^{\circ} \mathrm{C}, 8 \mathrm{~h}\right)$. Filters were stored at $-20{ }^{\circ} \mathrm{C}$ prior to drying $\left(60{ }^{\circ} \mathrm{C}\right)$, and 146 analysis with an elemental analyzer (Carlo Erba NA-1500) standardized using chitin.

147 Chlorophyll $a$ was determined by fluorescence against a standard chl $a$ solution according to the 148 method of Holm-Hansen et al. (1965). 
Heme $b$ concentrations were determined in phytoplankton after extraction into ammoniacal detergent (Gledhill 2007). In this study we used octyl $\beta$-glucopyranoside (OGP) as the detergent, to allow for determination of heme $b$ by mass spectrometry (Gledhill 2014). Samples were stored frozen at $-80^{\circ} \mathrm{C}$ prior to analysis. Heme $b$ was quantified, after separation from other pigments by high performance liquid chromatography - visible spectrophotometry using a diode array detector (DAD) (Gledhill 2007), and by selectively monitoring the major reactant ion (SRM of $\mathrm{m} / \mathrm{z}=557)$ produced by collision induced dissociation of heme $b(\mathrm{~m} / \mathrm{z}=616)$ using an ion trap mass spectrometer (ESI-MS, LTQ-Velos, Thermo Scientific) operating in the positive ion mode (Gledhill 2014). Source conditions were optimized, and the instrument tuned using standard iron (III) protoporphyrin IX. Masses were calibrated using the automatic instrument calibration procedure and a standard mass calibration solution (Thermo Scientific). Good agreement was observed between the two detection methods $\left([\text { heme }]_{\mathrm{DAD}}=1.06 \times[\text { heme }]_{\mathrm{SRM}}+3.6 \mathrm{pmol} \mathrm{L} \mathrm{L}^{-1}\right.$, $r^{2}=0.98, n=30$ ), with the intercept resulting in a potential difference of $<0.3 \%$ to the heme concentration in $C$. calcitrans cultures. Concentrations derived from SRM are used in the study, except for $C$. calcitrans, when a problem with the mass spectrometer meant that concentrations were calculated using visible spectrophotometry.

\section{Heme $b$ growth efficiency was calculated for phytoplankton in culture. Heme growth} efficiency is defined in analogy to iron use efficiency after Raven (1988), as the moles of carbon fixed per mole of heme $b$ per second. In culture, POC represents a good approximation for phytoplankton carbon and HGE was calculated from the growth rate $\left(\mathrm{s}^{-1}\right)$ and the heme $b$ : POC ratio according to the formula

$$
H G E=\mu \times\left(\frac{\text { heme } \mathrm{b}}{P O C}\right)^{-1}
$$


171 Apparent HGE in three areas of the ocean was also calculated by combining previously

172 published heme $b$ concentrations (Gledhill et al. 2013, Honey et al. 2013) with primary

173 productivity data obtained on the same cruises (Table 3; Poulton et al. 2010, Hickman et al.

174 2012, Korb et al. 2012) according to the formula

$175 \quad$ apparent $H G E=\frac{P P\left(\mathrm{~mol} \mathrm{C} \mathrm{m}^{-2} \mathrm{~s}^{-1}\right)}{[\text { heme } \mathrm{b}]\left(\mathrm{mol} \mathrm{m}^{-2}\right)}$

176 For field data we add the term "apparent" as there are several uncertainties in both the

177 determination of primary productivity and heme $b$ due to approximations made in the

178 calculations, methodological constraints and the complexity of community composition (Honey

179 et al. 2013, Juranek \& Quay 2013). Integrated heme $b$ concentrations were recalculated to match

180 the depths for the published integrated primary productivity data. Thus, for the Celtic Sea, heme

$181 b$ concentrations were integrated over the whole water column and compared to the median total

182 water column primary productivity given in Table 2 from Hickman et al. (2012). In the Scotia

183 Sea, our stations SSC4, SSP24 and SSP28 had mixed layer depths and integrated chl $a$

184 characteristic of "MID", "SW-SG" and "NW-SG" respectively and heme $b$ was thus integrated

185 to upper mixed layer depths given in Table 2 of Korb et al. (2012). In order to calculate HGE for

186 the Iceland Basin, heme $b$ was integrated to the mixed layer depth given in Table 1 of Poulton et

187 al. (2010).

Statistical analysis of results was carried out in the software package Sigmaplot ${ }^{\circ}$ v12.5

189 using analysis of variance, or non-parametric analysis of variance in cases of non-normal data

190 distributions. 


\section{Results}

193

\subsection{Growth rates}

Growth rates and $F_{v} / F_{m}$ for the five species are presented in Figure 1. The Southern Ocean species had growth rates of up to $0.5 \mathrm{day}^{-1}$ and $\mathrm{F}_{\mathrm{v}} / \mathrm{F}_{\mathrm{m}}$ up to 0.5 in SOs or SOs+Fe, similar to values reported previously for Southern Ocean species growing near ambient iron concentrations (Timmermans et al. 2004, Hoffmann et al. 2008, Strzepek et al. 2011). In contrast, Chaetoceros calcitrans repeatedly failed to grow in SOs or SOs+Fe while P. globosa was able to grow in SOs+DFB, SOs and SOs+Fe, albeit with very low growth rates (0.13-0.20 day $\left.{ }^{-1}\right)$ and with significantly reduced $\mathrm{F}_{\mathrm{v}} / \mathrm{F}_{\mathrm{m}}(\mathrm{p}<0.01)$. Consequently these two species were grown in enrichedSOs, with added vitamins, EDTA and trace metals, when growth rates of $>0.7$ day $^{-1}$ and $\mathrm{F}_{\mathrm{v}} / \mathrm{F}_{\mathrm{m}}>0.6$ were observed, values more typical for iron replete conditions. No attempt was made to grow the Southern Ocean species in enriched SOs.

\subsection{Culture media nutrient and iron concentrations}

Concentrations of nitrate, phosphate and silicate in the culture media at the beginning of the experiments were $27.4 \pm 1.0,1.7 \pm 0.1$ and $64.9 \pm 0.7 \mu \mathrm{mol} \mathrm{L}^{-1}$ respectively $(\mathrm{n}=6)$. None of the species grown in these experiments completely reduced the nitrate, phosphate or silicate inventories in SOs or SOs+DFB to levels below the detection limit (Table 1). Of the Southern Ocean species, $P$. antarctica consumed the most nitrate, with concentrations of nitrate depleted to levels below detection in SOs+Fe (Table 1). The amount of nitrate converted to PON in each bottle in experiments with no added iron, for experiments with $P$. antarctica was rather variable even though the total nitrogen (i.e. nitrate $+\mathrm{PON}$ ) calculated for each bottle was close to the concentration of nitrate determined at the start of the experiment $(108 \pm 14 \%$ for SOs+DFB and 
$97 \pm 7 \%$ for SOs). For cultures of $P$. globosa and C. calcitrans grown in enrichedSOs, dissolved

215 nitrate was completely removed from the media, and particulate organic nitrogen concentrations

216 were determined to be $95 \pm 16 \%(n=6)$ and $82 \pm 0.04 \%(n=7)$ of the starting nitrate

217 concentrations, respectively.

218

219

220

221

222

223

224

225

226

227

228

229

230

231 232 pmol L $\mathrm{L}^{-1}$ inorganically complexed iron (Fe') in SOs.

Iron concentrations in SOs averaged $0.35 \pm 0.17 \mathrm{nmol} \mathrm{L}^{-1}(\mathrm{n}=5)$ for the experiments on $C$. brevis and C. dichaeta, and $0.29 \pm 0.01 \mathrm{nmol} \mathrm{L}^{-1}(\mathrm{n}=3)$ for experiments on Phaeocystis sp. The natural ligand concentrations in SOs were very similar to the iron concentration $(0.36 \pm 0.03$ $\left.\mathrm{nmol} \mathrm{Eq} \mathrm{Fe} \mathrm{L}{ }^{-1}(\mathrm{n}=2)\right)$ and conditional stability constants $\left(\log K_{F e L_{i}\left(F e^{3+}\right)}^{c o n d}=22.4 \pm 0.01 \mathrm{~mol}^{-1}\right.$, at $20{ }^{\circ} \mathrm{C}$ ) were typical for open ocean ligands (Gledhill \& Buck 2012). Iron concentrations were not measured in enriched SOs treatments. Dissolved iron concentrations and speciation were also determined in SOs treatments at the end of experiments on $P$. antarctica $(0.33 \pm 0.21, \mathrm{n}=2), C$. dichaeta $(0.2 \pm 0.03, \mathrm{n}=3)$ and $P$. globosa $(0.36 \pm 0.31, \mathrm{n}=3)$. Iron concentrations were thus not significantly reduced during the course of the experiments ( $\mathrm{t}$-test, $p<0.05)$. The observed increase in variability was likely indicative of small amounts of iron contamination occurring during the course of the experiment. Similarly, ligand concentrations and stability constants did not change so that the overall average for ligand concentrations at the time that cells were harvested was $0.24 \pm 0.14 \mathrm{nmol} \mathrm{Eq} \mathrm{Fe} \mathrm{L}{ }^{-1}(\mathrm{n}=6)$ and the $\log K_{F e L_{i}\left(F e^{3+}\right)}^{\text {cond }}$ was $22.8 \pm 0.5,(\mathrm{n}=6)$. A simple ion pairing model (van den Berg 1984) was used to estimate a concentration of approximately 4

\subsection{Heme b concentrations}

We present here the heme $b$ concentrations (i.e. pmoles heme $b$ per liter culture media) at the 235 end of the growth period, in order to relate them to the dissolved iron concentrations in a semi- 
236

237

238

239

240

241

242

243

244

245

246

247

248

249

250

quantitative mass balance approach. The lowest particulate heme $b$ concentrations were observed in cultures of $C$. brevis in SOs+DFB (Fig. 2). In these C. brevis cultures approximately $1.0 \pm 0.5$ $\%$ of the dissolved iron present at the beginning of the experiment was incorporated into heme $b$. Particulate heme $b$ concentrations were higher in $C$. dichaeta cultures when compared to the other Southern Ocean species. For $C$. dichaeta cultured in SOs, heme $b$ concentrations represented $14 \pm 9 \%$ of the total dissolved iron inventory at the start of the experiments. Heme $b$ concentrations for $P$. antarctica and $P$. globosa were intermediate in value between $C$. brevis and C. dichaeta and no significant differences were observed between SOs, SOs+DFB and SOs+Fe treatments $(p<0.01)$ for analysis of variance between treatments within species. Heme $b$ concentrations observed in C. calcitrans and P. globosa cultured in enriched SOs were an order of magnitude higher than heme $b$ concentrations observed in unenriched SOs (i.e. cultures grown without added trace metals, EDTA and vitamins), reaching a maximum of $2930 \pm 300 \mathrm{pmol} \mathrm{L}^{-1}$ for C. calcitrans grown with $150 \mathrm{nmol} \mathrm{L}{ }^{-1}$ iron (Fig. 2). At total iron concentrations of $15 \mathrm{nmol}$ $\mathrm{L}^{-1}, C$. calcitrans incorporated $8 \pm 1 \%$ of the total iron inventory into heme $b$.

\subsection{Heme b quotas, heme b:chlorophyll a ratios and heme growth efficiency}

$$
\text { In this study, heme } b \text { quotas }\left(\mu \mathrm{mol} \text { heme } b \mathrm{~mol}^{-1} \mathrm{C} \text { ) and heme } b \text { : chl } a\right. \text { did not show }
$$
significant variability between treatments within species (Fig. 3). However, significant differences in heme $b: \mathrm{C}$ were observed between species when all treatments were pooled $(p<0.01)$. Heme $b$ :C for $C$. brevis and $P$. antarctica were thus significantly lower than heme $b: \mathrm{C}$ observed for P. globosa and C. calcitrans, and also lower than those reported previously for other species (Honey et al. 2013). Heme $b$ : C reported for P. antarctica compare well (overall average $0.08 \pm 0.05 \mu \mathrm{mol} \mathrm{mol}^{-1}$ ) with $\mathrm{Fe}: \mathrm{C}$ ratios of 2.0-2.7 $\mu \mathrm{mol} \mathrm{mol}^{-1}$ previously reported for P. antarctica grown at similar iron concentrations (Strzepek et al. 2011) given that heme $b$ has 
259 been shown to make up between 1 and $40 \%$ of the total cellular iron pool in previous studies

260 (Honey et al. 2013). Heme $b: \mathrm{C}$ and $\mathrm{F}_{\mathrm{v}} / \mathrm{F}_{\mathrm{m}}$ were weakly correlated (Fig. 4; $r=0.55, p<0.01, n=46$ ),

261 as particularly low $\mathrm{F}_{\mathrm{v}} / \mathrm{F}_{\mathrm{m}}$ was observed for $P$. globosa grown in unenriched SOs treatments.

262 Comparison of heme $b$ with particulate organic nitrogen (Table 1) indicated that heme $b: \mathrm{N}$ ratios

263 increased in treatments where nitrate was completely exhausted.

Heme $b$ was also significantly reduced relative to chl $a$ for both $P$. antarctica and $C$. brevis compared to P. globosa and C. calcitrans (Fig. 3B). Heme $b$ was observed to be three orders of magnitude lower than chl $a$ in these small Southern Ocean species, so that the relative

267 abundances of heme $b$ and chl $a$ were similar to those observed in particulate material sampled in 268 high latitude, iron deplete waters of the North Atlantic and Scotia Sea (Gledhill et al. 2013).

269 Relative abundances of heme $b$ and chl $a$ in $C$. dichaeta were intermediate in value, while the 270 relative abundances of heme $b$ and chl $a$ in $P$. globos $a$ and $C$. calcitrans were similar to those 271 reported previously for Phaeodactylum tricornutum, Thalassiosira oceanica, T. weissflogii and 272 Synechococcus sp. (Honey et al. 2013). In this study, no significant trends in the relative 273 abundance of heme $b$ and chl $a$ were observed with changing iron availability.

The impact of changes in heme $b$ on growth was examined through calculation of the heme 275 growth efficiency (HGE). Comparison within species indicated that a significantly lower HGE 276 was observed for C. brevis and P. globosa when grown with low iron availability (Fig. 5). When 277 treatments were pooled (omitting treatments with significantly lower HGE), the small Southern 278 Ocean species $P$. antarctica and C. brevis were both observed to have significantly higher HGE 279 than $C$. calcitrans and there was an overall trend of decreasing HGE in the order P. antarctica > 280 C. brevis $>$ C. dichaeta $\approx P$. globosa $\approx$ C. calcitrans. 
We calculated apparent HGE for the Celtic Sea, a coastal, iron replete region (Hickman et al.

282

283

284

285

286

287

288

289

290

291

292

293

294

295

296

297

298

299

300

301

302

303

2012, Honey et al. 2013), the Iceland Basin (Poulton et al. 2010, Gledhill et al. 2013), a high

latitude, seasonally iron limited region (Nielsdottir et al. 2009), and the Scotia Sea (Korb et al.

2012, Nielsdottir et al. 2012), a productive region of the Southern Ocean. Data used in these

calculations are presented in Table 2. Integrated heme $b$ concentrations were recalculated to

match depths for reported integrated primary productivity data (Table 2) and results are

presented in Fig. 6. Apparent HGE for the Celtic Sea averaged $2 \pm 1 \mathrm{~mol} \mathrm{C}$ mol heme $b^{-1} \mathrm{~s}^{-1}$

$(n=4)$, while HGE ranged from 1 to $4.2 \mathrm{~mol} \mathrm{C}$ mol heme $b^{-1} \mathrm{~s}^{-1}(n=3)$ in the Scotia Sea and from $1.0 \mathrm{~mol} \mathrm{C}$ mol heme $b^{-1} \mathrm{~s}^{-1}$ up to $27 \mathrm{~mol} \mathrm{C}$ mol heme $b^{-1} \mathrm{~s}^{-1}(n=10)$ in the high latitude North Atlantic.

\section{Discussion}

We compared heme $b$ concentrations in batch cultures of the Southern Ocean haptophyte $P$. antarctica and the diatoms $C$. brevis and $C$. dichaeta to that in the temperate coastal species $P$. globosa and $C$. calcitrans. We selected $P$. globosa and $C$. calcitrans because they are similar in size to $P$. antarctica and $C$. brevis (cell volumes approximately $100 \mu^{3}$ for Phaeocystis sp., $C$. brevis and C. calcitrans as opposed to approximately $4000 \mu \mathrm{m}^{3}$ for $C$. dichaeta), but they were isolated from coastal environments (North West Europe and Japan, respectively) and thus represented a contrast to the Southern Ocean species with respect to potential iron requirements. It was interesting to note that our coastal species grew very poorly or not at all in unenriched SOs. While the contrasting growth of our Southern Ocean and coastal species in SOs was in accordance with variations in iron requirements reported previously (Timmermans et al. 2005, Hoffmann et al. 2008, Lane et al. 2009, Strzepek et al. 2011), our experiments do not allow us to identify low iron concentrations as the sole cause for the low growth rates of the coastal species, 
as multiple trace elements and vitamins were added to the enriched media. Nevertheless,

305 particulate heme $b$ concentrations in our experiments increased with iron concentration (Fig. 2)

306 with up to one sixth of dissolved iron converted to heme $b$ when iron concentrations were similar

307 to those observed in the ocean. Interestingly, even for $C$. calcitrans, heme $b$ concentrations were

$3088 \pm 1 \%$ of the total iron inventory in cultures containing $15 \mathrm{nM}$ dissolved iron, suggesting that a

309 large proportion of the total dissolved iron was utilized by this species at this iron concentration.

Closer examination of the different treatments suggests that there are interspecies differences with respect to the influence of the chemical speciation of iron on heme $b$ concentrations. The strong iron chelator DFB reduced growth in $C$. brevis and prevented sustained growth for $C$. dichaeta, but made little difference to the amount of heme $b$ produced by $P$. antarctica and $P$.

314 globosa in our experiments. These results agree with previous studies showing that iron in DFB 315 is not universally unavailable to eukaryotic phytoplankton (Strzepek et al. 2011, Shaked \& Lis 316 2012). Furthermore, in our experiments, addition of iron as $\mathrm{FeCl}_{3}$ (SOs+Fe treatments) had only 317 a slight impact on particulate heme $b$ concentrations for all the species that grew in $\mathrm{SOs}+\mathrm{Fe}$ (Fig.

318 2). This is likely a result of losses of the added iron to the bottle walls or as precipitates, as 319 natural ligands were saturated or very close to saturation in SOs. The contrast between heme $b$ 320 concentrations observed with SOs+Fe when compared to experiments with enriched SOs 321 highlights the importance of ligands as iron buffers, keeping iron in solution, and thus potentially 322 available for uptake (Sunda et al. 2005, Gerringa et al. 2012, Thuróczy et al. 2012). 
327 in macronutrient utilization resulted from the relief of iron limitation alone as the enriched media

328 involved addition of a suit of trace metals and vitamins in addition to iron. However, an increase

329 in heme $b$ could be directly linked to increased exploitation of nitrate in enriched SOs via an

330 increased ability to undertake cytochrome $b_{557}$ dependent assimilatory nitrate reduction.

331 Assimilatory nitrate reduction has previously been shown to be reduced in iron limited

332 phytoplankton (Timmermans et al. 1994). Furthermore heme $b$ in assimilatory eukaryotic nitrate

333 reductase is likely to be labile for our extraction protocol (Gledhill et al. 2013, Honey et al. 2013)

334 as the protein is structurally similar to sulfite oxidase (Hille 2013) in which heme $b$ is relatively

335 exposed. However, this potential link between heme $b$ and nitrate reduction is undermined by

336 results from experiments on $P$. antarctica, which removed all the available nitrate in SOs+Fe,

337 without any observable increase in heme $b$ concentrations.

Low iron quotas have previously been observed in Southern Ocean phytoplankton (Hassler \& Schoemann 2009, Strzepek et al. 2011). However, the abundance of the intracellular content of 340 more specific iron pools has not previously been widely investigated. Here, we show that small 341 Southern Ocean species also have low heme $b$ quotas (Fig. 3). Furthermore, while heme $b$ was 342 reduced relative to $\mathrm{POC}$ in $P$. antarctica and $C$. brevis, chl $a$ :C ratios were not reduced so that 343 the relative abundances of heme $b$ and chl $a$ were similar to those observed in low iron regions of 344 the Scotia Sea and Iceland Basin (Gledhill et al. 2013). Low heme $b$ relative to chl $a$ had not 345 been observed in the diatom species examined previously (Honey et al. 2013), but in this study 346 C. brevis, a Southern Ocean diatom tolerant to low iron concentrations, also had low heme $b$ 347 relative to chlorophyll $a$. This study thus supports previous work that has linked decreases in the 348 abundance of heme $b$ relative to chl $a$ in the ocean (Honey et al. 2013, Gledhill 2014) to low 349 nutrient availability and the consequent changes in species composition. 
Heme $b$ is required to fix carbon in eukaryotes as it is a component of the photosystem

351 protein complexes cytochrome $\mathrm{b}_{6} f$ and photosystem II. Previous work has shown a correlation

352 between heme $b$ quota and $\mathrm{F}_{\mathrm{v}} / \mathrm{F}_{\mathrm{m}}$, the quantum yield of photosystem II (Honey et al. 2013). The

353 weaker correlation observed in this study was highly influenced by the results obtained when $P$.

354 globosa was grown in unenriched SOs. It is possible that $P$. globosa in unenriched SOs was not

355 truly acclimated to the conditions and that this was then reflected in the comparison between

$356 \quad \mathrm{~F}_{\mathrm{v}} / \mathrm{F}_{\mathrm{m}}$ and the heme $b$ quota. Nevertheless, the observed trend between $\mathrm{F}_{\mathrm{v}} / \mathrm{F}_{\mathrm{m}}$ and heme $b$ quota

357 does suggest that, in the majority of treatments, there could be a link between a lower quantum

358 yield of PSII and heme $b$ quota, and that lower heme $b$ may thus impact on growth. In this study,

359 we examined the relationship between growth and heme $b$ quotas through calculation of HGE

360 (equation 1). Decreasing HGE suggests that low heme $b$ quotas have a direct impact on growth,

361 while higher HGE indicates that the heme $b$ quota can be optimized. Reduced HGE was

362 observed at low iron concentrations for $C$. brevis and $P$. globosa, suggesting that decreased heme

$363 b$ did result in a growth cost. However, growth rates for P. antarctica and C. brevis in SOs and

364 SOs+Fe were relatively high (Fig. 1) despite the low intracellular heme $b$ concentrations, leading

365 to high HGE (Fig. 5) and suggesting that optimization of heme $b$ quota may be a mechasnism by

366 which a species can reduce its iron use whilst maintaining growth at low iron concentrations.

Results for HGE could be influenced by the nature of the extraction protocol used for heme $b$

368 determination. Both protein structure and intracellular localization may impact on heme $b$

369 extraction efficiency. The extraction protocol used in this study has been shown to be biased

370 towards heme $b$ molecules that are relatively accessible to attack by solvents (Gledhill et al.

371 2013, Honey et al. 2013). Examination of crystal structures suggests heme $b$ in the photosystem

372 cytochromes $b_{6}$ and $b_{559}$ is at least moderately extractable with our protocol (Stroebel et al. 2003, 
373 Muh et al. 2008). Furthermore, the heme $b$ in cytochrome $b_{559}$ has been shown to be labile in

374 detergent solution at high pH (Weber et al. 2011). Although we cannot state with confidence

375 which hemoprotein pool is impacted by reductions in heme $b$, our observed variations in HGE

376 indicate that reduced heme $b$ does not necessarily result in reduced growth and that individual

377 phytoplankton species are likely to optimize iron use by manipulating the intracellular

378 hemoprotein pool.

379 It was notable that in our study $P$. antarctica showed a remarkable ability to both fix carbon 380 and utilize nitrate, despite low intracellular heme $b$ concentrations. Our results suggest that 381 species such as $P$. antarctica can produce approximately ten times more particulate carbon than, 382 for example, $P$. globosa, given the same iron and nitrogen resource. Heme $b$ makes up an 383 important fraction of the total cellular iron pool. Our work is consistent with previous studies 384 (Strzepek et al. 2011) that have also shown an increase in iron use efficiency in small Southern 385 Ocean species such a $P$. antarctica, even though our experiments did not incorporate such a long 386 adaptation time as Strzepek et al. (2011), and our species may not have been fully acclimated to 387 the low iron treatments. Our work thus suggests that a low heme $b$ quota and the ability to 388 exploit a wide variety of iron sources likely contribute to the mechanisms by which $P$. antarctica 389 can efficiently exploit iron inputs (Marsay et al. 2014) in areas such as the Ross Sea, where this 390 species can form large blooms, resulting in the drawdown of $\mathrm{CO}_{2}$ (Tagliabue \& Arrigo 2005).

In field samples, heme $b$ in non photosynthesizing plankton could potentially act to decrease 392 apparent HGE, and differences in methodologies used to determine primary productivity could 393 also bias our results (Halsey et al. 2010). However, despite these potential offsets, our calculated 394 apparent HGE obtained from heme $b$ concentrations and primary productivity determined for 395 coastal (Celtic Sea) and open ocean (High Latitude North Atlantic-HLNA- and Scotia Sea) 
regions were within the range calculated in our phytoplankton cultures. In the Scotia Sea, HGE was not as high as that observed for P. antarctica as the Scotia Sea tends to be dominated by diatoms or dinoflagellates (Korb et al. 2010, Korb et al. 2012). The highest HGE was thus observed in the HLNA at stations characterized by iron concentrations $<0.05 \mathrm{nmol} \mathrm{L}^{-1}$, i.e. stations IB285 and IB260 (Gledhill et al. 2013). Thus the lower levels of heme $b$ that have been observed in low iron open ocean environments (using this extraction technique) do not necessarily imply low growth or productivity. In fact, increased HGE is necessary in areas with low heme $b$ relative to chl $a$, in order to comply with observed correlations between productivity and chlorophyll $a$ (e.g. Poulton et al. 2010).

In this study we have shown that small, Southern Ocean phytoplankton had low heme $b$ quotas. Species with low heme $b$ quotas did not necessarily exhibit low growth rates, suggesting that heme $b$ quotas were optimized, possibly in order to reduce overall iron requirements. We furthermore compared previously published field data with primary productivity and also found that low heme $b$ relative to chlorophyll $a$ was not necessarily associated with decreased productivity. Our results suggest considerable variability with respect to heme $b$ quotas amongst marine phytoplankton in culture, and that this variability may also be observed in the field. Heme $b$ quotas could change as a result of optimization of biological iron pools and also be influenced by methodological constraints imposed by the extraction protocol. Irrespective of the cause, the finding that a particular iron pool is reduced in phytoplankton growing at low iron concentrations, both in the laboratory and in the field, and that the reduction in this important iron pool does not impact proportionately on carbon accumulation, sheds further light on how marine phytoplankton can adapt to low iron, open ocean environments. 
419 The authors would like to thank the anonymous reviewers for their constructive comments on the

420 manuscript. MG was supported by a Natural Environment Research Council Advanced Fellowship

421 (NE/E013546/1). The authors would like to thank A. Noordeloos (NIOZ) for her help with PAM

422 fluorescence and flow cytometry, S. Akbari (UoS) for his assistance with POC/N analysis and M.

423 Esposito (UoS) for his assistance with the nutrient analysis.

424 


\section{References}

Croot PL, Johansson M (2000) Determination of iron speciation by cathodic stripping voltammetry in seawater using the competing ligand 2-(2-Thiazolylazo)-p-cresol (TAC). Electoanalysis 12:565576

De Baar HJW, De Jong JTM (2001) Distribution, sources and sinks of iron in seawater. In: Turner DR, Hunter KA (eds) The biogeochemistry of iron in seawater. Wiley, Chichester

De Baar HJW, Timmermans KR, Laan P, De Porto HH, Ober S, Blom JJ, Bakker MC, Schilling J, Sarthou G, Smit MG, Klunder M (2008) Titan: A new facility for ultraclean sampling of trace elements and isotopes in the deep oceans in the international Geotraces program. Mar Chem 111:4-21

Erdner DL, Price NM, Doucette GJ, Peleato ML, Anderson DM (1999) Characterization of ferredoxin and flavodoxin as markers of iron limitation in marine phytoplankton. Marine Ecology-Progress Series 184:43-53

Espinas NA, Kobayashi K, Takahashi S, Mochizuki N, Masuda T (2012) Evaluation of unbound free heme in plant cells by differential acetone extraction. Plant Cell Physiol 53:1344-1354

Gerringa LJA, Alderkamp A-C, Laan P, Thuróczy C-E, De Baar HJW, Mills MM, van Dijken GL, van Haren H, Arrigo KR (2012) Iron from melting glaciers fuels the phytoplankton blooms in Amundsen Sea (Southern Ocean): Iron biogeochemistry. Deep Sea Research Part II: Topical Studies in Oceanography 71-76:16-31

Gerringa LJA, Rijkenberg MJA, Thuróczy C-E, Maas LRM (2014) A critical look at the calculation of the binding characteristics and concentration of iron complexing ligands in seawater with suggested improvements. Environmental Chemistry 11:114-136

Gledhill M (2007) The determination of heme $b$ in marine phyto- and bacterioplankton. Mar Chem 103:393-403

Gledhill M (2014) The detection of iron protoporphyrin (heme b) in phytoplankton and marine particulate material by electrospray ionisation mass spectrometry - comparison with diode array detection. Anal Chim Acta 841:33-43

Gledhill M, Achterberg EP, Honey DJ, Nielsdottir MC, Rijkenberg MJA (2013) Distributions of particulate heme $b$ in the Atlantic Ocean and Southern Ocean - implications for electron transport in phytoplankton. Global Biogeochemical Cycles 27:1-11

Gledhill M, Buck KN (2012) The organic complexation of iron in the marine environment: A review. Frontiers in Microbiology 3:69

Grasshoff K, Ehrhardt M, Kremling K (1983) Methods of Seawater Analysis. Verlag Chemie, Weinheim

Halsey K, Milligan A, Behrenfeld M (2010) Physiological optimization underlies growth rate-independent chlorophyll-specific gross and net primary production. Photosynthesis Research 103:125-137

Hassler CS, Schoemann V (2009) Bioavailability of organically bound Fe to model phytoplankton of the Southern Ocean. Biogeosciences 6:2281-2296

Hickman AE, Moore CM, Sharples J, Lucas MI, Tilstone GH, Krivtsov V, Holligan PM (2012) Primary production and nitrate uptake within the seasonal thermocline of a stratified shelf sea. Mar Ecol Prog Ser 463:39-57

Hille R (2013) The molybdenum oxotransferases and related enzymes. Dalton Transactions 42:30293042

Hoffmann L, Peeken I, Lochte K (2008) Iron, silicate, and light co-limitation of three Southern Ocean diatom species. Polar Biology 31:1067-1080

Hogle SL, Barbeau KA, Gledhill M (2014) Heme in the marine environment: from cells to the iron cycle. Metallomics 6:1107-1120 
Holm-Hansen O, Lorenzen CJ, Holmes RW, Strickland JDH (1965) Fluorometric Determination of Chlorophyll. Journal du Conseil 30:3-15

Honey DJ, Gledhill M, Bibby TS, Legiret FE, Pratt NJ, Hickman AE, Lawson T, Achterberg EP (2013) Heme b in marine phytoplankton and particulate material from the North Atlantic Ocean. Mar Ecol Prog Ser 483:1-17

Hopkinson BM, Roe KL, Barbeau KA (2008) Heme uptake by Microscilla marina and evidence for heme uptake systems in the genomes of diverse marine bacteria. Appl Env Microbiol 74:6263-6270

Juranek LW, Quay PD (2013) Using triple isotopes of dissolved oxygen to evaluate global marine productivity. Annual Review of Marine Science 5:503-524

Kawachi M, Noel M-H (2005) Sterilization and sterile techniques. In: Anderson RA (ed) Algal culturing techniques. Elsevier, China

Korb RE, Whitehouse MJ, Gordon M, Ward P, Poulton AJ (2010) Summer microplankton community structure across the Scotia Sea: implications for biological carbon export. Biogeosciences 7:343356

Korb RE, Whitehouse MJ, Ward P, Gordon M, Venables HJ, Poulton AJ (2012) Regional and seasonal differences in microplankton biomass, productivity, and structure across the Scotia Sea: Implications for the export of biogenic carbon. Deep Sea Research II 59-60:67-77

Lane ES, Semeniuk DM, Strzepek RF, Cullen JT, Maldonado MT (2009) Effects of iron limitation on intracellular cadmium of cultured phytoplankton: Implications for surface dissolved cadmium to phosphate ratios. Mar Chem 115:155-162

Marsay CM, Sedwick PN, Dinniman MS, Barrett PM, Mack SL, McGillicuddy DJ (2014) Estimating the benthic efflux of dissolved iron on the Ross Sea continental shelf. Geophysical Research Letters 41:2014GL061684

Muh F, Renger T, Zouni A (2008) Crystal structure of cyanobacterial photosystem II at 3.0 angstrom resolution: A closer look at the antenna system and the small membrane-intrinsic subunits. Plant Physiology and Biochemistry 46:238-264

Nielsdottir M, Bibby TS, Moore CM, Hinz DJ, Sanders R, Whitehouse MJ, Korb RE, Achterberg EP (2012) Seasonal dynamics of iron availability in the Scotia Sea. Mar Chem 130-131:62-72

Nielsdottir MC, Moore CM, Sanders R, Hinz DJ, Achterberg EP (2009) Iron limitation of the postbloom phytoplankton communities in the Iceland Basin. Global Biogeochemical Cycles 23:GB3001

Peers G, Price NM (2006) Copper-containing plastocyanin used for electron transport by an oceanic diatom. Nature 441:341-344

Poulton AJ, Charalampopoulou A, Young JR, Tarran GA, Lucas MI, Quartly GD (2010) Coccolithophore dynamics in non-bloom conditions during late summer in the central Iceland Basin (July-August 2007). Limnol Oceanogr 55:1601-1613

Qi ZH, O'Brian MR (2002) Interaction between the bacterial iron response regulator and ferrochelatase mediates genetic control of heme biosynthesis. Mol Cell 9:155-162

Raven JA (1988) The iron and molybdenum use efficiencies of plant-growth with different energy, carbon and nitrogen-sources. New Phytologist 109:279-287

Raven JA (1990) Predictions of Mn and Fe use efficiencies of phototrophic growth as a function of light availability for growth and of $C$ assimilation pathway. New Phytologist 116:1-18

Richaud C, Zabulon G (1997) The heme oxygenase gene (pbsA) in the red alga Rhodella violacea is discontinuous and transcriptionally activated during iron limitation. Proc Natl Acad Sci USA 94:11736-11741

Roe KL, Hogle SL, Barbeau KA (2013) Utilization of heme as an iron source by marine alphaproteobacteria in the Roseobacter clade. Appl Env Microbiol 79:5753-5762 
Saito MA, Bertrand EM, Dutkiewicz S, Bulygin VV, Moran DM, Monteiro FM, Follows MJ, Valois FW, Waterbury JB (2011) Iron conservation by reduction of metalloenxyme inventories in the marine diazotroph Crocosphaera watsonii. Proc Natl Acad Sci USA 108:2184-2189

Shaked Y, Lis H (2012) Disassembling iron availability to phytoplankton. Frontiers in Microbiology 3

Shekhawat GS, Verma K (2010) Haem oxygenase (HO): an overlooked enzyme of plant metabolism and defence. Journal of Experimental Botany 61:2255-2270

Smith LJ, Kahraman A, Thornton JM (2010) Heme proteins-Diversity in structural characteristics, function, and folding. Proteins: Structure, Function, and Bioinformatics 78:2349-2368

Stroebel D, Choquet $Y$, Popot JL, Picot D (2003) An atypical haem in the cytochrome b(6)f complex. Nature 426:413-418

Strzepek RF, Harrison PJ (2004) Photosynthetic architecture differs in coastal and oceanic diatoms. Nature 431:689-692

Strzepek RF, Maldonado MT, Hunter KA, Frew RD, Boyd PW (2011) Adaptive strategies by Southern Ocean phytoplankton to lesson iron limitation: Uptake of organically complexed iron and reduced iron requirements. Limnol Oceanogr 56:1983-2002

Sunda WG, Huntsman SA (1995) Iron uptake and growth limitation in oceanic and coastal phytoplankton. Mar Chem 50:189-206

Sunda WG, Price NM, Morel FMM (2005) Trace metal ion buffers and their use in culture studies. In: Anderson RA (ed) Algal Culturing Techniques. Elsevier

Sunda WG, Swift DG, Huntsman SA (1991) Low iron requirement for growth in oceanic phytoplankton. Nature 351:55-57

Tagliabue A, Arrigo KR (2005) Iron in the Ross Sea: 1. Impact on $\mathrm{CO}_{2}$ fluxes via variation in phytoplankton functional group and non-Redfield stoichiometry. J Geophys Res-Oceans 110

Tanaka R, Tanaka A (2007) Tetrapyrrole biosynthesis in higher plants. Annual Review of Plant Biology 58:321-346

Thuróczy C-E, Alderkamp A-C, Laan P, Gerringa LJA, Mills MM, Van Dijken GL, De Baar HJW, Arrigo KR (2012) Key role of organic complexation of iron in sustaining phytoplankton blooms in the Pine Island and Amundsen Polynyas (Southern Ocean). Deep Sea Research Part II: Topical Studies in Oceanography 71-76:49-60

Timmermans KR, Stolte W, de Baar HJW (1994) Iron-mediated effects on nitrate reductase in marine phytoplankton. Marine Biology 121:389-396

Timmermans KR, van der Wagt B, de Baar HJW (2004) Growth rates, half-saturation constants, and silicate, nitrate, and phosphate depletion in relation to iron availability of four large, open-ocean diatoms from the Southern Ocean. Limnol Oceanogr 49:2141-2151

Timmermans KR, van der Wagt B, Veldhuis MJW, Maatman A, de Baar HJW (2005) Physiological responses of three species of marine pico-phytoplankton to ammonium, phosphate, iron and light limitation. Journal of Sea Research 53:109-120

van den Berg CMG (1984) Organic and inorganic speciation of copper in the Irish Sea. Mar Chem 14:201212

Weber M, Prodohl A, Dreher C, Becker C, Underhaug J, Svane ASP, Malmendal A, Nielsen NC, Otzen D, Schneider D (2011) SDS-facilitated in vitro formation of a transmembrane b-type cytochrome is mediated by changes in local pH. Journal of Molecular Biology 407:594-606 
Table 1. Concentrations of nitrate, phosphate, silicate, particulate organic carbon (POC), particulate organic nitrogen (PON), chlorophyll $a(\mathrm{chl} a)$ and particulate heme $b$ observed in cultures of Southern Ocean (Phaeocystis antarctica,

Chaetoceros brevis and Chaetoceros dichaeta) and temperate coastal ( $P$. globosa and C. calcitrans) phytoplankton species at the end of the experiments. For $P$. antarctica data for nitrate, phosphate, POC and PON are presented individually ( $\mathrm{n}=1)$, because of high variability between experimental triplicates. Chlorophyll $a$ and heme $b$ concentrations and all data for other species are given as the mean \pm SD for experimental triplicates. <d.1.: less than the detection limit; n.d.: not determined.

$\begin{array}{ccccccc}\begin{array}{c}\text { Nitrate } \\ \left(\mu \mathrm{mol} \mathrm{L} \mathrm{L}^{-1}\right)\end{array} & \begin{array}{c}\text { Phosphate } \\ \left.(\mu \mathrm{mol} \mathrm{L})^{-1}\right)\end{array} & \begin{array}{c}\text { Silicate } \\ \left.(\mu \mathrm{mol} \mathrm{L})^{-1}\right)\end{array} & \begin{array}{c}\text { POC } \\ \left.(\mu \mathrm{mol} \mathrm{L})^{-1}\right)\end{array} & \begin{array}{c}\text { PON } \\ \left.(\mu \mathrm{mol} \mathrm{L})^{-1}\right)\end{array} & \begin{array}{c}\text { Chl } a \\ \left.(\mathrm{nmol} \mathrm{L})^{-1}\right)\end{array} & \begin{array}{c}\text { Heme } b \\ \left(\text { pmol L }^{-1}\right)\end{array}\end{array}$

Phaeocystis antarctica

\begin{tabular}{|c|c|c|c|c|c|c|c|}
\hline & 15.3 & 0.91 & n.d. & 69 & 10 & & \\
\hline \multirow[t]{3}{*}{ SOs } & $<$ d.l. & 0.17 & n.d. & 190 & 25 & $12 \pm 5$ & $8.2 \pm 0.5$ \\
\hline & 5.9 & 0.40 & n.d. & 119 & 22 & & \\
\hline & 10.9 & 0.46 & n.d. & 92 & 15 & & \\
\hline \multirow[t]{3}{*}{ SOs+DFB } & 1.4 & 0.05 & n.d. & 140 & 32 & $12 \pm 5$ & $10 \pm 3$ \\
\hline & 15.0 & 0.92 & n.d. & 70 & 13 & & \\
\hline & 0.4 & $<$ d.l. & n.d. & 284 & 22 & & \\
\hline \multirow[t]{2}{*}{$\mathrm{SOs}+\mathrm{Fe}$} & $<$ d. 1. & $<$ d.l. & n.d. & 114 & 19 & $16 \pm 5$ & $11 \pm 6$ \\
\hline & <d.l. & 0.10 & n.d. & 127 & 18 & & \\
\hline
\end{tabular}

Chaetoceros brevis

\begin{tabular}{lccccccc}
\hline SOs & $21.7 \pm 1.9$ & $1.35 \pm 0.05$ & $63.7 \pm 0.8$ & $35 \pm 7$ & $3.7 \pm 0.8$ & $6.6 \pm 2.7$ & $7.7 \pm 3.0$ \\
SOs+DFB & $25.5 \pm 0.2$ & $1.58 \pm 0.14$ & $65.5 \pm 0.5$ & $6.2 \pm 1.1$ & $1.1 \pm 0.3$ & $1.1 \pm 0.4$ & $2.4 \pm 0.5$ \\
SOs+Fe & $16.5 \pm 3.4$ & $1.00 \pm 0.11$ & $58.2 \pm 4.4$ & $36 \pm 4$ & $5.9 \pm 1.0$ & $13 \pm 2$ & $13 \pm 3$ \\
\hline \multicolumn{7}{c}{ Chaetoceros dichaeta } \\
SOs & $12.3 \pm 4.2$ & $0.70 \pm 0.27$ & $38.0 \pm 8.9$ & $52 \pm 13$ & $7.3 \pm 1.5$ & $6.9 \pm 1.6$ & $49 \pm 30$ \\
SOs+Fe & $15.6 \pm 1.9$ & $0.75 \pm 0.14$ & $43.4 \pm 2.3$ & $48 \pm 12$ & $7.3 \pm 2.1$ & $11 \pm 1$ & $47 \pm 6$ \\
\hline
\end{tabular}

Phaeocystis globosa 


\begin{tabular}{|c|c|c|c|c|c|c|c|}
\hline SOs & $24.6 \pm 1.0$ & $1.61 \pm 0.05$ & n.d. & $16 \pm 4$ & $2.6 \pm 0.3$ & $1.8 \pm 0.6$ & $24 \pm 4$ \\
\hline SOs+DFB & $24.8 \pm 0.5$ & $1.64 \pm 0.02$ & n.d. & $14 \pm 3$ & $1.6 \pm 0.1$ & $1.4 \pm 0.2$ & $16 \pm 1$ \\
\hline $\mathrm{SOs}+\mathrm{Fe}$ & $22.0 \pm 2.8$ & $1.44 \pm 0.16$ & n.d. & $16 \pm 4$ & $2.5 \pm 0.6$ & $1.8 \pm 0.5$ & $35 \pm 8$ \\
\hline $\begin{array}{l}\text { enrichedSOs } \\
(9 \mathrm{nM})\end{array}$ & $<$ d.l. & $<$ d.l. & n.d. & $457 \pm 50$ & $29 \pm 4$ & $49 \pm 3$ & $528 \pm 26$ \\
\hline $\begin{array}{l}\text { enrichedSOs } \\
(45 \mathrm{nM})\end{array}$ & $<$ d.l. & $<$ d.l. & n.d. & $482 \pm 11$ & $22.3 \pm 1.9$ & $56 \pm 4$ & $800 \pm 200$ \\
\hline \multicolumn{8}{|c|}{ Chaetoceros calcitrans } \\
\hline $\begin{array}{l}\text { enrichedSOs } \\
(15 \mathrm{nM})\end{array}$ & $<$ d.l. & $<$ d.l. & $51.1 \pm 0.4$ & $540^{1}(\mathrm{n}=1)$ & $20^{1}(\mathrm{n}=1)$ & $61 \pm 7$ & $1170 \pm 80$ \\
\hline $\begin{array}{l}\text { enrichedSOs } \\
(45 \mathrm{nM})\end{array}$ & $<$ d.l. & $<$ d.l. & $50.5 \pm 0.1$ & $560 \pm 34$ & $19 \pm 1$ & $63 \pm 3$ & $1430 \pm 80$ \\
\hline $\begin{array}{l}\text { enrichedSOs } \\
(150 \mathrm{nM})\end{array}$ & $<$ d.l. & $<$ d.l. & $50.9 \pm 2.9$ & $480 \pm 140$ & $21 \pm 1$ & $76 \pm 9$ & $2000 \pm 200$ \\
\hline
\end{tabular}

${ }^{1}$ Two samples lost during analysis 
Table 2. Integrated primary productivity, heme $b$ and heme growth efficiency (HGE) calculated from previously published field data.

\begin{tabular}{|c|c|c|c|}
\hline Station & $\begin{array}{l}\text { Integrated primary productivity } \\
\left(\mathrm{mmol} \mathrm{C} \mathrm{m}{ }^{-2} \mathrm{day}^{-1}\right)\end{array}$ & $\begin{array}{l}\text { Integrated heme } b \\
\quad\left(\text { nmol m}^{-2}\right)\end{array}$ & $\begin{array}{l}\text { HGE (mol C (mol } \\
\left.\text { heme } b)^{-1} \mathrm{~s}^{-1}\right)\end{array}$ \\
\hline \multicolumn{4}{|c|}{ Celtic Sea ${ }^{I}$} \\
\hline B21 & 201 & 174 & 1.1 \\
\hline B22 & 369 & 217 & 1.6 \\
\hline OB1 & 251 & 276 & 0.9 \\
\hline $\mathrm{U} 2$ & 273 & 103 & 2.6 \\
\hline \multicolumn{4}{|c|}{ Scotia Sea ${ }^{2}$} \\
\hline SSC4 & 17 & 270 & 0.6 \\
\hline SSP28 & 29 & 114 & 2.6 \\
\hline SSP3 & 233 & 579 & 4.2 \\
\hline \multicolumn{4}{|c|}{ Iceland Basin ${ }^{3}$} \\
\hline IB204 & 17 & 70 & 2.8 \\
\hline IB209 & 11 & 115 & 1.1 \\
\hline IB212 & 23 & 81 & 3.2 \\
\hline IB222 & 10 & 31 & 3.7 \\
\hline IB226 & 41 & 44 & 11 \\
\hline IB243 & 49 & 76 & 7.4 \\
\hline IB260 & 41 & 19 & 25 \\
\hline IB274 & 28 & 27 & 12 \\
\hline IB285 & 65 & 28 & 27 \\
\hline IB286 & 41 & 59 & 7.9 \\
\hline
\end{tabular}

1. Median integrated primary productivity data for the whole water column were obtained from Hickman et al. (2012). Integrated heme $b$ was calculated from Honey et al. (2013). 
2. Primary productivity data was obtained from Korb et al. (2012). We used values for "MID", "SW-SG" and "NW-SG" as these regions had integrated chl $a$ values that closely corresponded with values we calculated for integrated chl $a$ at stations SSC4, SSP28 and SSP3 respectively. We adjusted our values for integrated heme $b$ using the upper mixed layer depth given in Korb et al. (2012).

3. Primary productivity data was obtained from Poulton et al. (2010). Integrated heme $b$ from data in Gledhill et al. (2013) was recalculated for depths given in Poulton et al. (2010). 

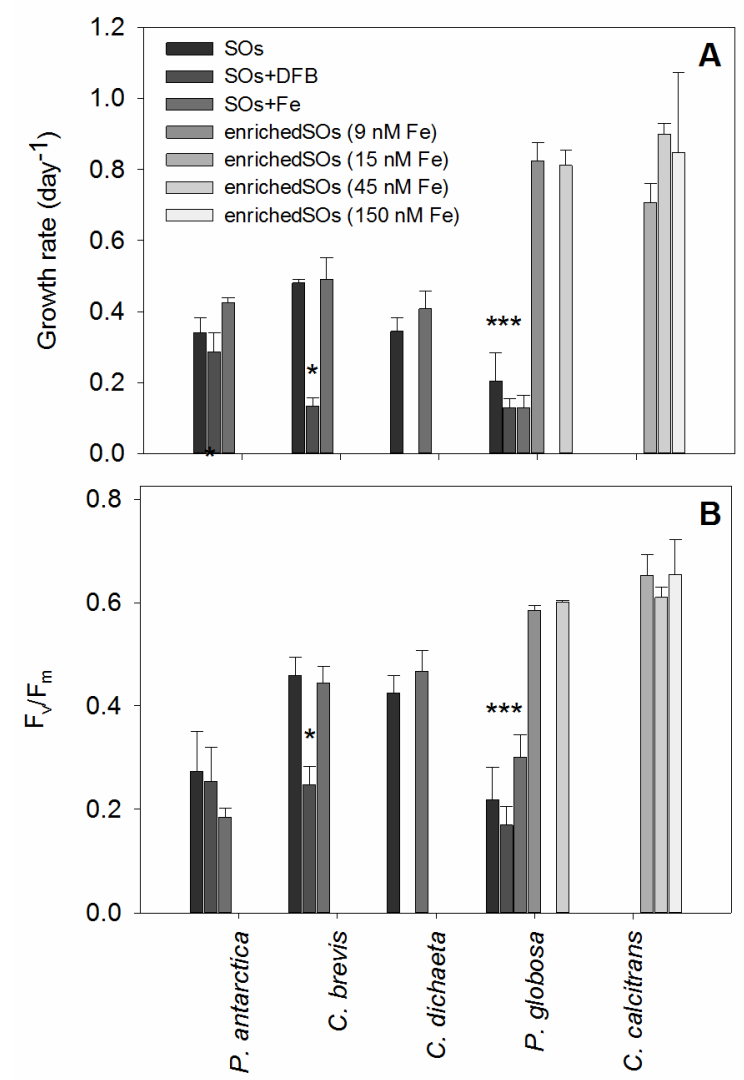

Figure 1. (A) Growth rates $\left(\right.$ day $\left.^{-1}\right)$ and $(B) F_{v} / F_{m}$ for the Southern Ocean and coastal phytoplankton grown in Southern Ocean seawater (SOs) with added desferrioxamine (DFB), Fe, and trace metals plus ethylenediaminetetraacetic acid (EDTA) (enriched SOs). Southern Ocean species (Phaeocystis antarctica, Chaetoceros calcitrans and $C$. dicheata) were not grown in enrichedSOs. Growth in SOs+DFB could not be maintained for Chaetoceros dichaeta. Values are means \pm SD. Significant differences (One way ANOVA on Ranks, $p<0.01$ ) between treatments within species are denoted by *. 


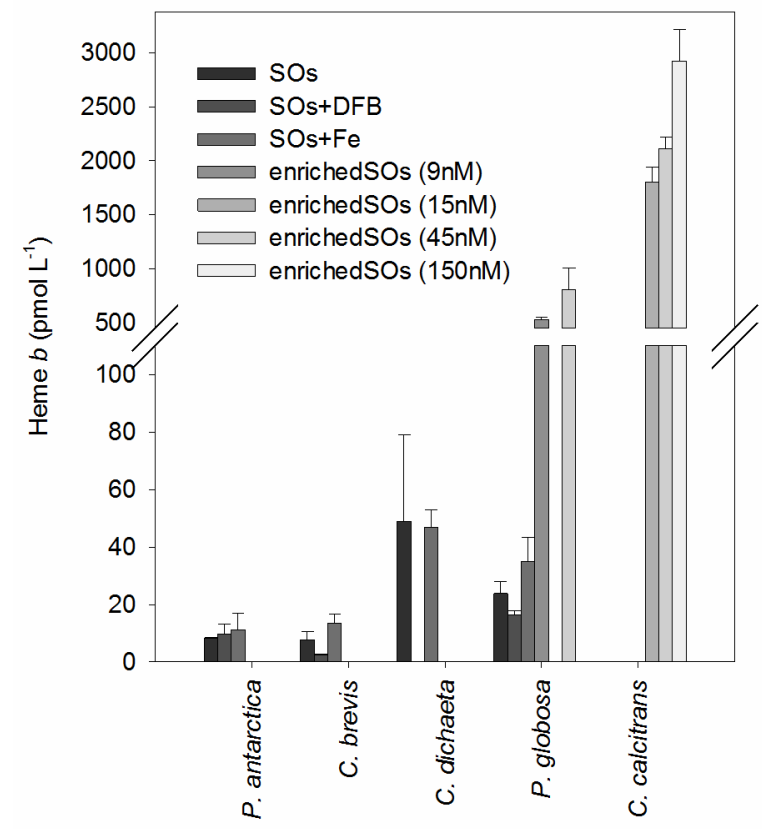

Fig. 2. Heme $b$ concentrations ( $\mathrm{pmol} \mathrm{L}^{-1}$ ) observed at the end of the exponential phase in Southern Ocean and coastal phytoplankton grown in Southern Ocean seawater treatments. Values are means \pm SD. 

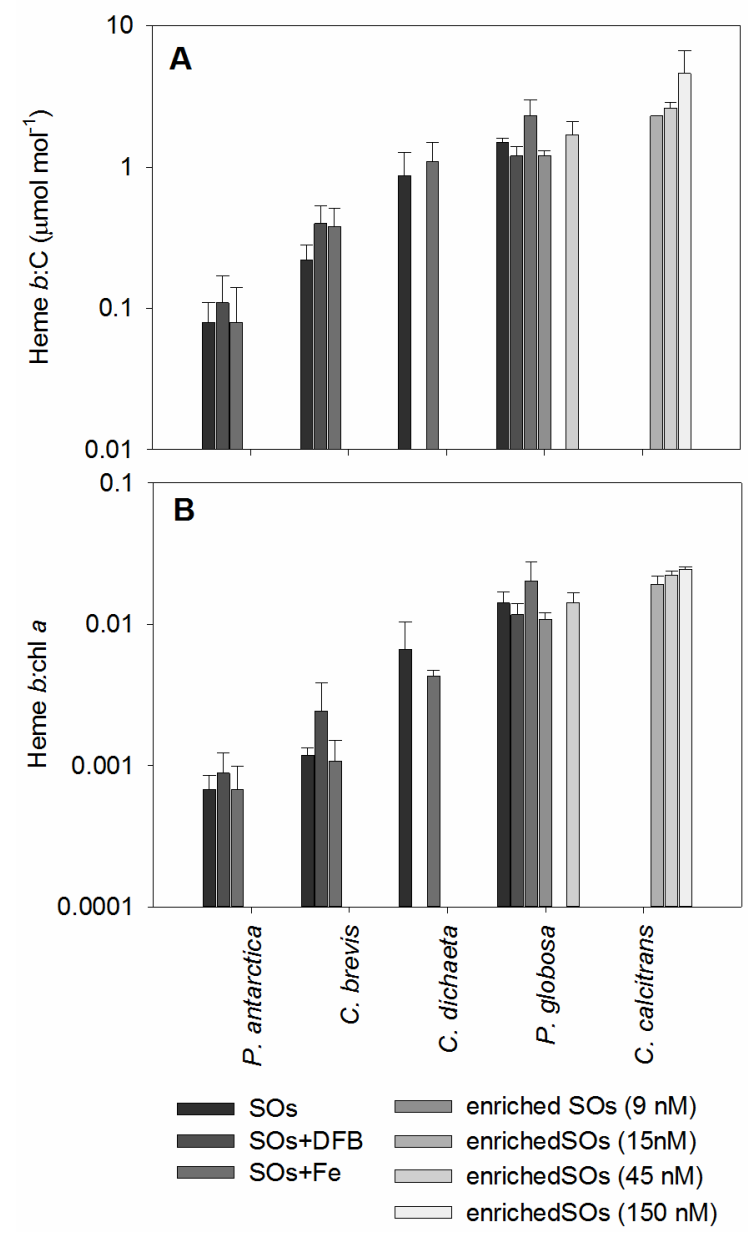

Figure 3. Intracellular heme $b$ concentrations expressed relative to $(\mathrm{A})$ carbon $\left(\mu \mathrm{mol} \mathrm{mol}{ }^{-1}\right)$ in Southern Ocean and coastal phytoplankton species and (B) chlorophyll $a$ (expressed as the molar ratio) in Southern Ocean and coastal phytoplankton species. Values are means \pm SD. Note log scale on y axis. 


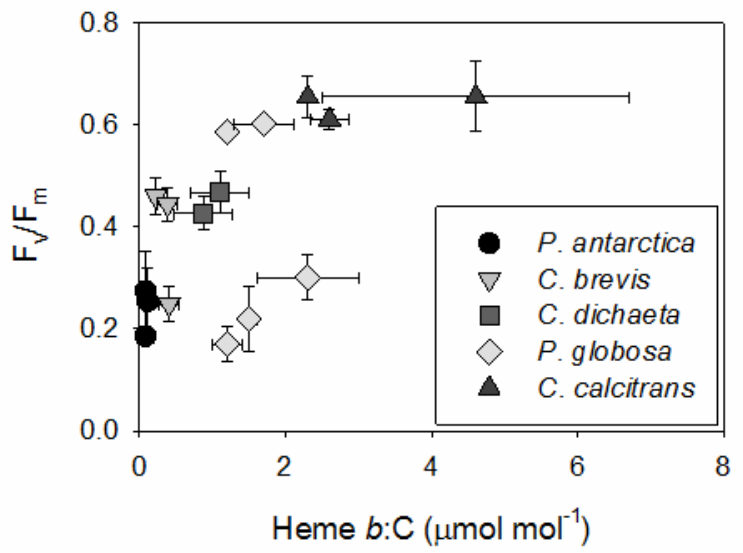

Figure 4. Relationship between heme $b: \mathrm{C}\left(\mu \mathrm{mol} \mathrm{mol}{ }^{-1}\right)$ and $\mathrm{F}_{\mathrm{v}} / \mathrm{F}_{\mathrm{m}}$ in Southern Ocean and coastal phytoplankton species in this study. 


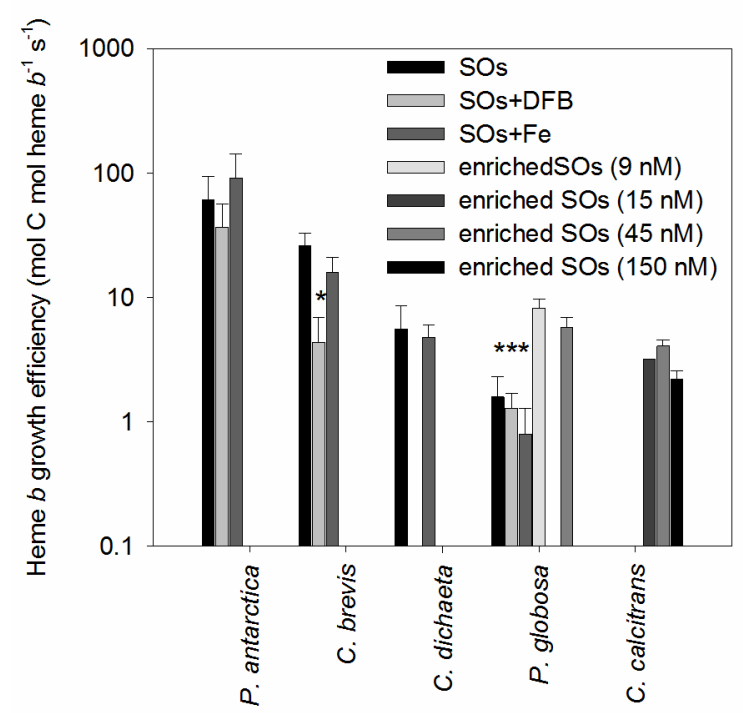

Figure 5. Heme growth efficiency (HGE, mol C mol heme $\mathrm{b}^{-1} \mathrm{~s}^{-1}$ ), determined for Southern Ocean and coastal species in our experiments. Values are means \pm SD. Significant differences between treatments within species are denoted by * (One way ANOVA on Ranks, $\mathrm{p}<0.01$ ). Note log scale on y axis. 


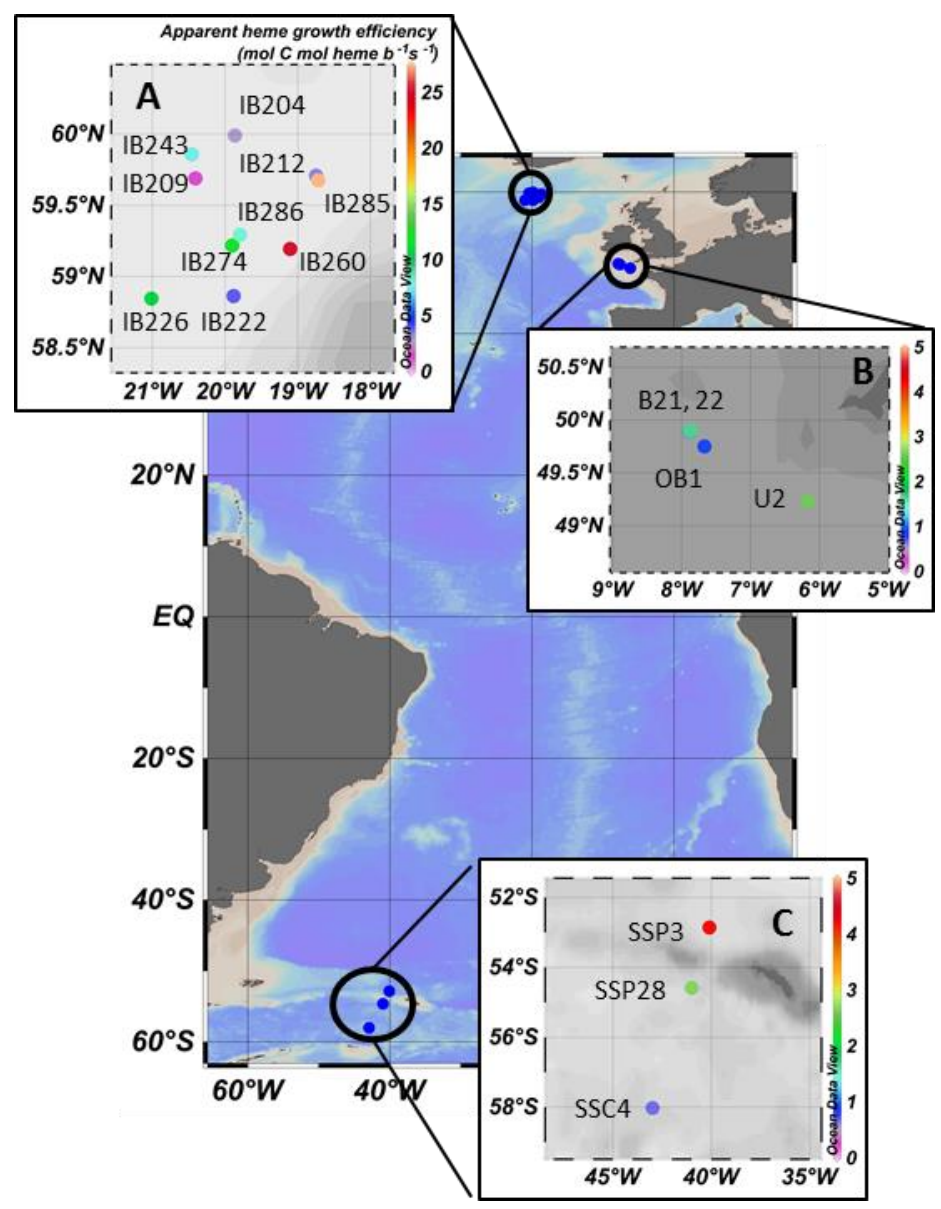

Figure 6. Heme growth efficiency (HGE, mol C mol heme $\mathrm{b}^{-1} \mathrm{~s}^{-1}$ ) in (A) the Iceland Basin, (B) the Celtic Sea and (C) the Scotia Sea. HGE was determined for integrated mixed layer depths (Scotia Sea, Iceland Basin) or whole water column depths (Celtic Sea) from previously published productivity data (Poulton et al. 2010, Hickman et al. 2012, Korb et al. 2012) and heme $b$ concentrations (Gledhill et al. 2013, Honey et al. 2013). Note scale change for Iceland Basin. Color bar denotes HGE for all inset figures. Background colors represent bathymetry (light grey: 250-2000 m; dark grey: < $250 \mathrm{~m}$ ) 